\title{
Hydatid Cyst in Cerebellum: A Rare Case Report
}

\author{
Amit Kumar Ghosh ${ }^{1}$ \\ ${ }^{1}$ Department of Neurosurgery, Global Hospital, Chennai, \\ Tamil Nadu, India \\ Indian J Neurosurg 2016;5:140-141.
}

\begin{abstract}
Address for correspondence Amit Kumar Ghosh, DNB, Embassy Residency, Perumbakkam, Saraswati-Rajasekhar Salai, Chennai, Tamil Nadu 600100, India (e-mail: amitghosh74@yahoo.co.in).
\end{abstract}

\begin{abstract}
Hydatid cyst in the cerebellum is extremely rare. This is a case report of cerebellar hydatid cyst in a 60-year-old man presented with truncal ataxia. CT and MRI scan of the brain was done and hydatid cyst was suspected. Complete microsurgical excision was done using the Dowling technique.

Keywords

- cerebellar hydatid cyst The patient recovered well. He was given albendazole for 1 month. Histopathology confirmed the diagnosis of hydatid cyst. Literature was reviewed and the disease was analyzed.
\end{abstract}

\section{Introduction}

The hydatid cyst is the larval form of the tapeworm Echinococcus granulosus. ${ }^{1,2}$ Humans are the intermediate hosts in the parasite's lifecycle. ${ }^{1}$ Hydatid disease is transferred to human by ingestion of food contaminated by the scolex, or eggs, or by direct contact with dog. ${ }^{1}$ The hydatid cyst reaches the brain after passing through the liver and the lungs. ${ }^{1}$ The majority of such cysts remain in the liver and lungs; only 1 to $2 \%$ of the cysts reach the brain., ${ }^{1,2}$

A 60-year-old man presented with walking difficulty due to truncal ataxia. Computed tomography (CT) and magnetic resonance imaging (MRI) scan of the brain (-Fig. 1) was done and it showed a cystic midline cerebellar lesion. Hydatid cyst was suspected. Midline suboccipital craniectomy (-Fig. 2) and complete excision of that cyst were done using the Dowling technique. ${ }^{3,4}$ Histopathology showed (-Fig. 3) the features of hydatid cyst. ${ }^{5}$ One-month postoperative course of albendazole $(10 \mathrm{mg} / \mathrm{kg})$ was given. ${ }^{1,3}$ Patient recovered well over next 3 months.

\section{Discussion}

Cerebral hydatid cyst is very rare comprising just 1 to $2 \%$ of all cases of hydatid disease. ${ }^{2}$ In India, the hydatid disease is more commonly seen in Andhra Pradesh, Tamil Nadu, and Punjab. In
India, incidence of intracranial hydatids cyst is $0.2 \%{ }^{2}$ Intracranial hydatid cysts are more frequently located in the supratentorial compartment. Parietal lobe is the most common site. $^{2}$ The other less common sites reported include the skull, cavernous sinus, eyeball, pons, extradural region, cerebellum, and ventricles. ${ }^{2}$ Cerebellar hydatid cyst is rarer. Only two cases were reported. ${ }^{1,5}$ Our case is probably the third case.

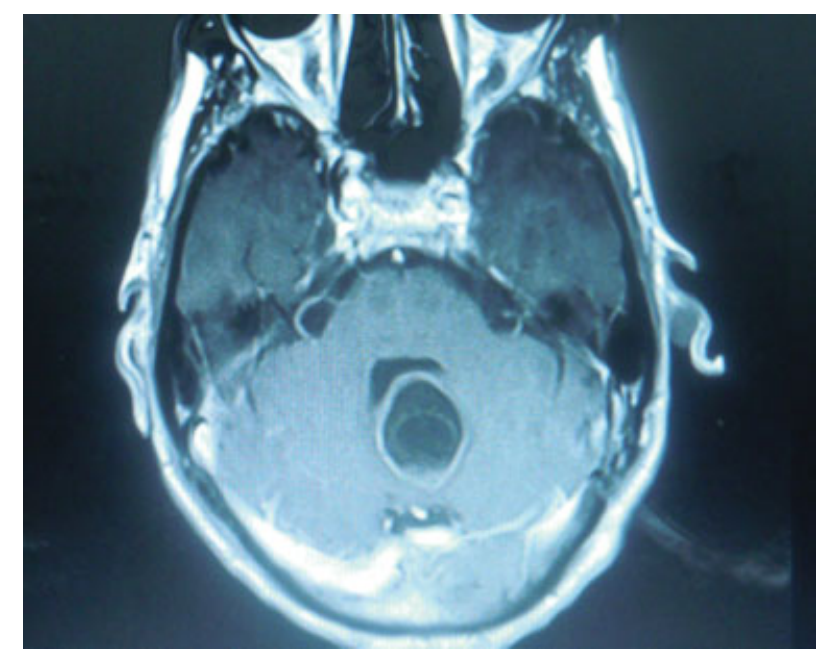

Fig. 1 Preoperative contrast MRI showing the suspected hydatid cyst. received

December 29, 2015

accepted

February 10, 2016

published online

July 19, 2016
DOI http://dx.doi.org/

10.1055/s-0036-1584588. ISSN 2277-954X. (c) 2016 Neurological Surgeons' Society of India
License terms

(ब) (1) $\circledast$ 


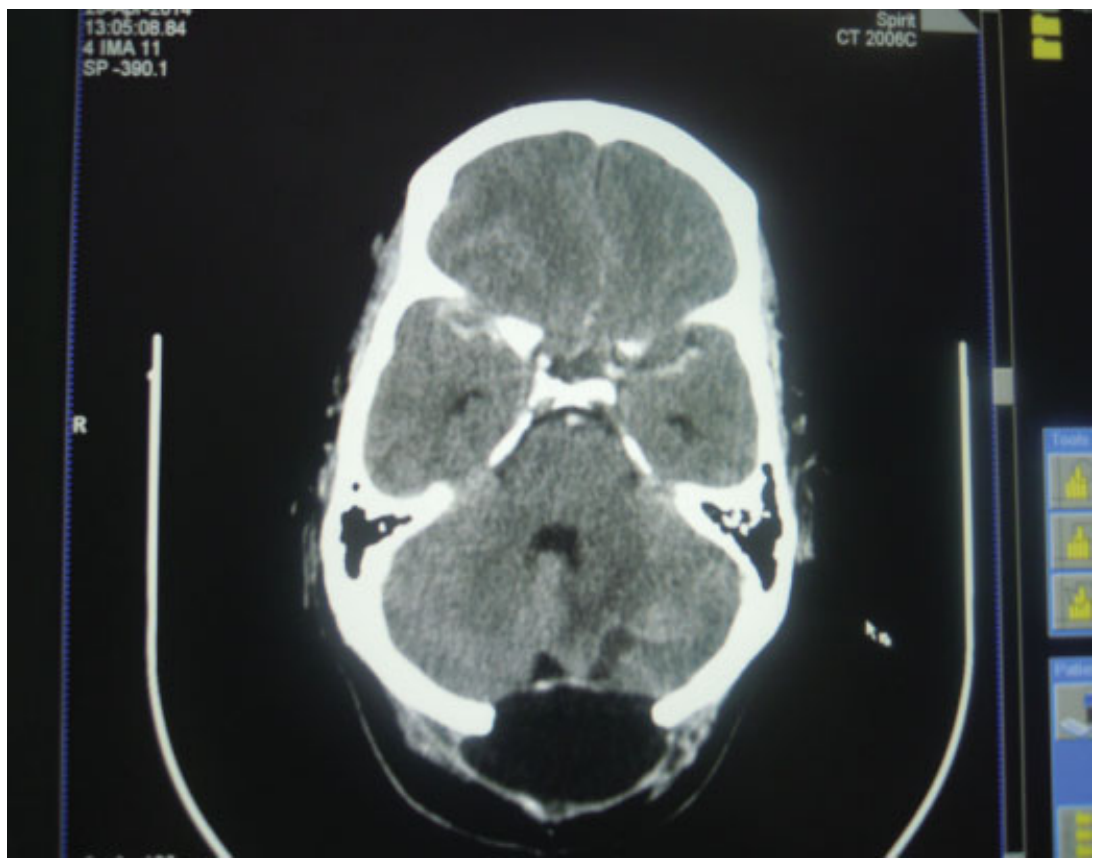

Fig. 2 Postoperative CT scan of the brain showing complete excision of cyst.

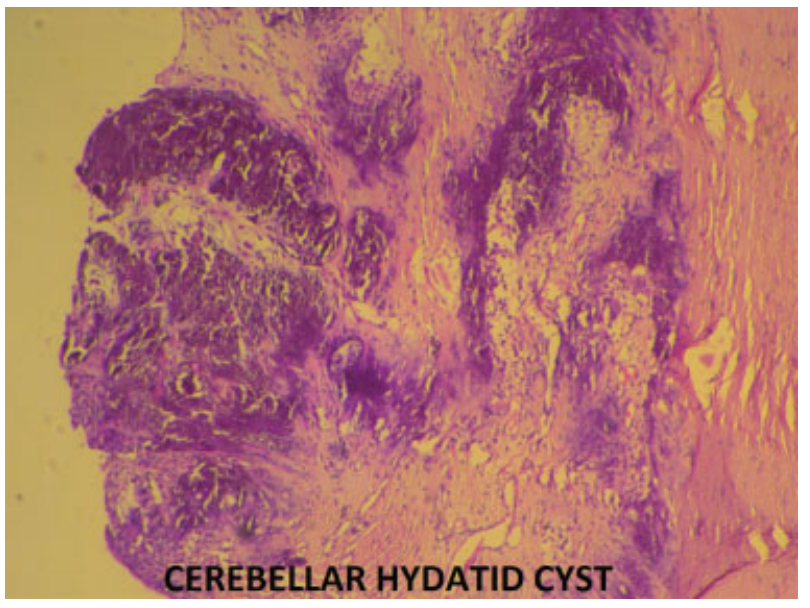

Fig. 3 H\&E stain showing prominent investing cuticle and brood capsules.

\section{Source(s) of Support}

None.

Conflict of Interest

None.

\section{References}

1 Kayaoglu CR. Giant hydatid cyst in the posterior fossa of a child: a case report. J Int Med Res 2008;36(1):198-202

2 Gupta S, Desai K, Goel A. Intracranial hydatid cyst: a report of five cases and review of literature. Neurol India 1999;47(3):214-217

3 Umerani MS, Abbas A, Sharif S. Intra cranial hydatid cyst: a case report of total cyst extirpation and review of surgical technique. J Neurosci Rural Pract 2013;4(Suppl 1):S125-S128

4 Carrea R, Dowling E Jr, Guevara JA. Surgical treatment of hydatid cysts of the central nervous system in the pediatric age (Dowling's technique). Childs Brain 1975;1(1):4-21

5 Yasha TC, Shibu P, Srikanth SG, Shankar SK. 13-year-old boy with cerebellar cystic mass. Neurol India 2006;54(1):100-101 